\title{
Upaya Meningkatkan Pemahaman Gerak Dasar Lempar Lembing Melalui Penerapan Lembing Modifikasi Dalam Pembelajaran Atletik
}

\author{
*Diana Wijayanti ${ }^{1}$, Andi Suntoda Situmorang ${ }^{1}$ \\ ${ }^{1}$ Program Studi Pendidikan Guru Sekolah Dasar Pendidikan Jasmani, \\ Fakultas Pendidikan Olahraga dan Kesehatan, Universitas Pendidikan Indonesia \\ email :dianawijayanti@student.upi.edu
}

\begin{abstract}
Abstrak
Penelitian ini bertujuan untuk mengetahui peningkatan keterampilan gerak dasar lempar lembing dengan menggunakan lembing modifikasi pada siswa kelas V SDPN Setiabudhi Kota Bandung. Dari hasil observasi yang telah dilakukan sebelumnya, diketahui bahwa kemampuan siswa dalam melakukan gerak dasar lempar lembing masih rendah, sehingga mendorong peneliti untuk melakukan penelitian tindakan kelas (PTK), dengan memberikan tindakan intervensi sebanyak 3 siklus yang terdiri dari 6 tindakan. Analisa data dilakukan dengan mereduksi data dan memaparkan data dalam bentuk tabel, sehingga dapat dicari nilai rata-rata dan persentase ketuntasan belajar. Subjek penelitian berjumlah 35 orang, yang terdiri dari 17orang siswa putra dan 18 orang siswa putri. Hasil penelitian pada siklus I menunjukkan gerak dasar lempar lembing mencapai hasil $(52,80 \%)$, Pada siklus II menunjukkan bahwa gerak dasar lempar lembing mencapai peningkatan hingga $(80,17 \%)$, Pada siklus III menunjukan bahwa gerak dasar lempar lembing terdapat sedikit peningkatan yaitu $(82,17 \%)$. Penelitian ini menyimpulkan bahwa dengan menggunakan lembing modifikasi dapat meningkatkan gerak dasar lempar lembing pada siswa kelas V SDPN Setiabudhi Kota Bandung Tahun Ajaran 2016/2017.
\end{abstract}

Kata kunci: Gerak Dasar, Lempar Lembing, Modifikasi

*Diana Wijayanti adalah lulusan Program Studi PGSD Penjas, Departemen Pendidikan Olahraga, Fakultas Pendidikan Olahraga dan Kesehatan, Universitas Pendidikan Indonesia. 


\title{
Improvement Efforts To Understanding The Basic Javelin Movement Through Application Of Modified Javelin In Athletic Learning
}

\begin{abstract}
The purpose of this research is to improve children attainment of basic javelin movement through throwing activities using modified javelins for the grade V students of SDPN (Primary School) Setiabudhi Bandung, with overall number of 35 students, consisting of 17 male students and 18 female students. From the observations conducted prior to research, it was shown that students' ability in basic javelin movement is still low, that driven the writer to conduct intervention effort in form of classroom action research, employing three cycle with total of 6 actions. Then the data analysis is carried out with data reduction techniques and shown them in table. The average value and mastery learning percentage as the impact of the intervention activities finally can be determined. The result of the first cycle shows that basic javelin movements of children have reached $52,80 \%$ improvement, while in second cycle reached $80,17 \%$, and in the last cycle only improved slightly to about $82,17 \%$. As the conclusion, it is convinced that the attainment of children basic javelin movement has improved slighly better than that of using common traditional ways of teaching.

Keyword: Basic movement, javelin movement, modification javelin throw.
\end{abstract}

\section{PENDAHULUAN}

Pendidikan merupakan investasi besar jangka panjang yang harus di tata dan di siapkan sebaik mungkin, hal ini diakui oleh semua orang atau suatu bangsa demi untuk kelangsungan masa depannya. Demikian halnya dengan suatu bangsa yang menaruh harapan besar pada calon pendidik untuk kemajuan masa depan bangsanya, karena dari sanalah muncul tunastunas muda harapan bangsa sebagai generasi penerus dibentuk. Proses belajar berlangsung seumur hidup manusia, baik yang di dapat dalam kehidupan sehari-hari maupun dari proses pendidikan yang bersifat formal. Pendidikan formal memiliki tingkatan masing-masing untuk tingkat usia tertentu. Pendidikan memiliki tingkat jenjang masing-masing 
dimulai jenjang PAUD, SD, SMP, SMA, sampai dengan perguruan tinggi dan setiap jenjang pendidikan mempunyai tujuan masing-masing.

Contohnya saja dalam jenjang pendidikan Sekolah Dasar mempunyai tujuan untuk menanamkan kecerdasan, pengetahuan dasar, kepribadian, ahlak mulia, serta keterampilan untuk hidup mandiri. Dimana dalam pencapaian hasil yang baik peserta didik harus mampu menyelesaikan serangkaian mata pelajaran, dan salah satu mata pelajarannya yaitu pendidikan jasmani. Menurut Mahendra, (2015, hlm.18) Pendidikan jasmani adalah sebagai berikut : "Pendidikan jasmani adalah proses pendidikan melalui aktivitas jasmani, permainan atau olahraga yang terpilih untuk mencapai tujuan pendidikan.”

Menurut pendapat diatas bahwa penjas merupakan bagian yang tidak terpisahkan dari pendidikan umum, memiliki tujuan yang sama untuk membantu agar anak tumbuh dan berkembang dengan baik sesuai dengan tujuan pendidikan nasional, yaitu menjadi manusia Indonesia seutuhnya. Dalam proses pembelajaran pendidikan jasmani guru di harapkan mengajarkan berbagai keterampilan gerak dasar dan berbagai permainan dan olahraga, internalisasi nilai-nilai (sportifitas, jujur, kerjasama dan lainlain) serta pembiasaan pola hidup sehat. Pelaksanaannya tidak dilakukan di dalam kelas yang bersifat kajian teoritis, namun melibatkan unsur fisik, mental, intelektual, emosi dan sosial.

Pelaksanaan pendidikan jasmani merupakan modal yang sangat penting dalam upaya meningkatkan mutu sumber daya manusia, Karena melalui pendidikan jasmani anak dapat mengembangkan 3 aspek yang merupakan 
tujuan dari pendidikan aspek tersebut terdiri dari : kognitif, afektif, psikomotor. Salah satu materi pembelajaran berdasarkan kurikulum yang ada di sekolah dasar yaitu atletik. Atletik merupakan cabang olahraga yang meliputi jalan, lari, lompat dan lempar (Hendrayana, 2014).

Atletik merupakan suatu mata pelajaran yang wajib diberikan di sekolahsekolah Karena atletik merupakan ibu dari sebagian besar cabang olahraga dimana gerakan-gerakan yang ada di dalam atletik seperti : jalan, lari, lompat, dan lempar dimiliki oleh sebagian besar cabang olahraga. Salah satu bentuk pengajaran atletik yang seringkali diberikan di sekolah dasar adalah pembelajaran lempar lembing. lempar lembing adalah suatu bentuk gerakan melempar alat yang terbuat dari kayu panjang dan meruncing. Melempar merupakan keterampilan gerak manipulatif (Mahendra, 2017) yang biasa di lakukan bagi siswa sekolah dasar. Dalam upaya membina pengembangan kemampuan tersebut, guru harus mampu meningkatkan motivasi siswa untuk mengikutinya. Namun pada kenyataannya masih banyak siswa yang belum meminati pelajaran atletik bahkan cenderung mereka kurang menyukainya. Ini merupakan suatu tantangan untuk guru pendidikan jasmani agar pembelajaran atletik lebih menarik dan menyenangkan bagi siswanya jadi siswa merasa tidak kesulitan untuk melaksanakan tugas gerak tersebut.

Banyak kendala dan hambatan agar atletik disukai dan disenangi oleh siswa salah satu kendala yang sering ditemui di lapangan antara lain adalah kurang tersedianya fasilitas dan perlengkapan untuk kegiatan pembelajaran atletik yang memadai. Sebagai calon guru penjas, kreatifitas harus perlu di kembangkan dan di tingkatkan dengan mencoba 
memodifikasi peralatan atletik. Sebagai calon guru penjas harus dapat mengembangkan teknik-teknik pengajaran yang lebih digemari siswa sehingga dapat memberikan jalan keluar dari masalah yang di hadapi oleh para guru pendidikan jasmani dalam pembelajaran atletik yaitu teknik dasar lempar lembing, serta mampu memperbaiki proses pembelajaran pendidikan jasmani yang akhirnya mampu meningkakan pemahaman dan kemampuan siswa di bidang gerak dasar lempar lembing.

Masalah yang dihadapi peneliti yaitu ketika sedang mengajar pembelajaran atletik khususnya lempar lembing, pembelajaran kurang berjalan dengan baik, pembelajaran ateltik yang di anggap membosankan, tidak menarik dan kurang disenangi oleh siswa, peralatan yang kurang memadai sehingga menjadi salah satu alasan siswa kurang senang terhadap pembelajaran tersebut sehingga siswa kurang memahami gerak dasar lempar lembing. Untuk mengatasi dan meminimalisir permasalahan tersebut maka diperlukan kegiatan yang menarik minat belajar anak dan menyenangkan untuk dilakukan oleh anak, guru harus berusaha seoptimal mungkin dalam merancang tugas gerak yang menyenangkan, guru pendidikan jasmani di tuntut untuk berfikir kreatif dan inovatif dalam menggunakan berbagai alat modifikasi pembelajaran yang diharapkan mampu mengurangi permasalahan dalam pembelajaran atletik. Dengan menggunakan lembing modifikasi diharapkan mampu meningkatkan pemahaman gerak dasar lempar lembing siswa serta mengurangi dan memecahkan masalah-masalah yang yang timbul dalam pembelajaran lempar lembing. 


\section{METODE}

Penelitian yang digunakan peneliti ini adalah penelitian tindakan kelas (Classroom Action Research. Adapun yang menjadi partisipan atau subjek dalam penelitian ini adalah Siswa kelas V SDPN Setiabudhi, kota Bandung. Dengan Jumlah 17 siswa laki-laki dan 18 siswi Perempuan pada tahun pelajaran 2016/2017. Teknik pengumpulan data dengan observasi digunakan bila penelitian berkenaan dengan perilaku manusia, proses kerja, gejala-gejala alam dan bila responden yang diamati tidak terlalu besar.

Penilaian terhadap kemampuan psikomotorik anak dilakukan dengan tes penampilan atau peragaan, yang meliputi pengamatan terhadap gerakan awalan, gerakan utama, serta gerak akhir dari keterampilan yang dinilai. Masing-masing tes peragaan ini memiliki bobot tersendiri sesuai dengan keragamannya. Adapun daftar dokumen yang diperlukan dalam penelitian ini adalah gambar-gambar foto selama proses pembelajaran bagi anak kelas V di SDPN Setiabudhi. Catatan lapangan dalam penelitian ini digunakan untuk merangkum perubahan perkembangan gerak dasar siswa oleh observer dalam proses pembelajaran yang tidak terdapat dalam pedoman lembar observasi, sehingga catatan lapangan hanya sebagai pelengkap data berikut lembar catatan lapangan. Pengolahan data dilakukan dengan cara data reduction, data display, dan verifikasi.

\section{HASIL DAN PEMBAHASAN}

Dari hasil penelitian menggunakan observasi terdapat data awal sebesar 33,31\% lalu hasil dari tindakan 1 mengalami peningkatan menjadi $43,60 \%$. Begitu pun pada tindakan selanjutnya yaitu hasil dari tindakan 2 
hasil data yang didapat dari pengamatan gerak dasar lempar lembing siswa mengalami peningkatan menjadi 52,80\% hal tersebut dikarnakan siswa mulai memahami materi yang diberikan. Pada tindakan selanjutnya yaitu tindakan 3 hasil pengamatan gerak dasar lempar lembing siswa sebesar 63,26\% hasil tersebut meningkat dari tindakan sebelumnya. Pada tindakan 4 hasil pengamatan gerak dasar lempar lembing siswa sebesar $80,17 \%$, pada pengamatan terakhir yaitu tindakan 5 hasil pengamatan gerak dasar lempar lembing siswa sebesar 82,17\%. Berikut penulis sertakan grafik tentang perbandingan gerak lempar lembing siswa di setiap tindakannya seperti dibawah ini:

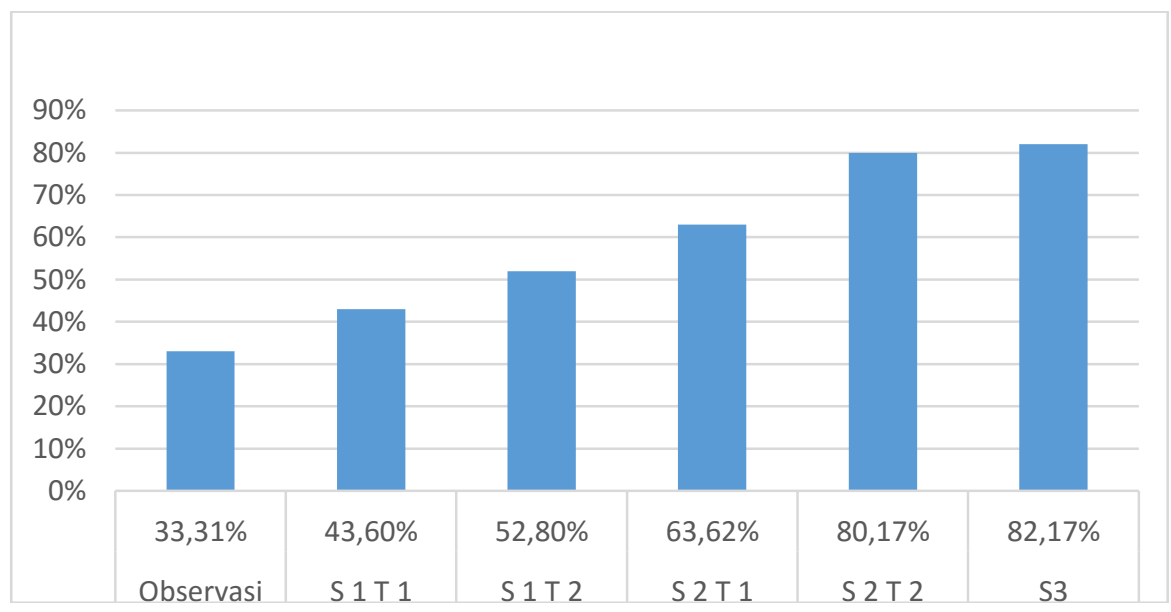

Gambar. 1

Grafik Perbandingan Gerak Dasar Lempar Lembing

Bedasarkan grafik hasil data observer disimpulkan bahwa gerak dasar lempar lembing siswa kelas V.C SDPN Setiabudhi Bandung bisa dikatakan cukup rendah, karena berdasarkan hasil penelitian pra observasi gerak dasar lempar lembing siswa kurang dari 70\% atau lebih tepatnya hanya 33,31\%. Maka dari itu peneliti melakukan pembelajaran pendidikan 
jasmani dengan menerapkan lembing modifikasi sebagai alat untuk meningkatkan gerak dasar lempar lembing.

Pada siklus 1 peneliti melakukan 2 tindakan, pada tindakan pertama peneliti memberikan materi sikap awalan ketika akan melakukan lemparan dengan menggunakan modifikasi bola berekor dan pada tindakan kedua peneliti memberikan materi sikap awalan dan peralihan ketika akan melakukan lempar menggunakan modifikasi bola berekor. Pada siklus ke 2 peneliti juga melakukan 2 tindakan, pada tindakan ketiga peneliti memberikan penarikan tongkat ke belakang dengan menggunakan modifikasi tongkat paralon dan pada tindakan keempat peneliti memberikan materi sikap akhir yaitu ketika tongkat lepas dari.

Dalam hasil pra observasi terlihat bahwa gerak dasar lempar lembing siswa 33,31\% dan pada tindakan 4 bahwa gerak dasar lempar lembing siswa mengalami peningkatan yang cukup tinggi 80,17\%. Pada siklus 3 peningkatan yang terjadi tidak cukup sedikit yaitu hanya 82,17 dari tindakan sebelumnnya hanya meningkat $2 \%$. Hasil tersebut sudah mencapai harapan peneliti, yaitu untuk meningkatkan gerak dasar lempar lembing > 80\%. Ini menunjukkan bahwa pembelajaran yang diberikan cukup menyenangkan dan menarik sehingga dapat meningkatkan gerak dasar lempar lembing dalam pembelajaran atletik.

\section{KESIMPULAN}

Kesimpulan dari hasil penelitian mengenai "Upaya Meningkatkan Pemahaman Gerak Dasar Lempar Lembing Melalui Penerapan Lembing Modifikasi Pada Pembelajaran Atletik (penelitian tindakan kelas siswa kelas V SDPN Setiabudhi Kota Bandung)". Yaitu Penerapan lembing 
modifikasi cocok diterapkan oleh guru pendidikan jasmani dalam proses pembelajaran lempar lembing di SD, karena penerapan lembing modifikasi ini dapat membuat anak lebih mudah dalam melakukan tugas gerak yang di berikan oleh guru serta mendapatkan hasil gerak yang lebih baik selain itu juga dapat membuat anak lebih senang dan merasa nyaman ketika melaksanakan tugas geraknya. Berdasarkan hasil analisis data penelitian yang penulis teliti dapat disimpulkan bahwa penerapan alat lembing modifikasi dapat meningkatkan pemahaman gerak dasar lempar lembing siswa kelas V.C SDPN Setiabudi Kota Bandung. 


\section{DAFTAR PUSTAKA}

Arikunto, S., Suhardjono., \& Supardi. (2015). Penelitian Tindakan kelas. Jakarta : PT Bumi Aksara.

Bahagia, Y., \& Mujianto, S. (2010). Fasilitas dan Perlengkapan Penjas. Bandung: FPOK

Barnett, L. (2012). Australian Children Lack The Basic Movement Skills to be Active and Healthy, hlm. 1-3

Budiman, D., \& Hidayat Y. (2010). Psikologi anak dalam pendidikan jasmani. Bandung: FPOK

D, Drost \& J, Todorovich. (2013). Enhancing Cognitive Understanding To Improve Fundamental Movement Skills, hlm. 54-59

Dimyati. \& Mudjiono. (2015). Belajar dan Pembelajaran. Jakarta : PT Rineka Cipta.

Djaelani, A. (2013). Teknik Pengumpulan Data dalam penelitian Kualitatif, xx (1), hlm. 86-87.

Hendrayana, Y (2014). Bermain Atletik.

Mahendra, Agus. (2015). Filsafat Pendidikan Jasmani: Dasar-dasar Pembelajaran Penjas di Sekolah Dasar. Bandung: CV. Bintang WarliArtika.

Mahendra, Agus (2017) Model Pendidikan Gerak (Movement Education) Dalam Pendidikan Jasmani. Modul. Bandung: FPOK-UPI.

Sagala, S. (2014) Konsep dan Makna Pembelajaran. Bandung : Alfabeta.

Subroto, T., Yudiana Y., \& Hidayat Y. (2016). Penulisan Penelitian Tindakan Kelas Dalam Pendidikan Jasmani, Olahraga, dan Kesehatan. Bandung : FPOK.

Suntoda, A. (2016). Bahan ajar PPT Tes Pengukuran, Evaluasi penjas dan Olahraga. Bandung : FPOK

Sugiyono. (2016). Metode Penelitian Pendidikan. Bandung : Alfabeta

Wiarto, G. (2013). Atletik. Yogyakarta : Graha Ilmu.

Indah, J. (2016). Meningkatkan Motivasi Dan Prestasi Belajar Olahraga Lempar Lembing Melalui Penerapan Lempar Roket Pada Siswa Kelas IV SD Negri02 Bulusari Kabupaten Tulung Agung. (Skripsi). Fakultas Keguruan dan Ilmu Pendidikan, Universitas Nusantara PGRI, Kediri.

Rustandi, (2013). Upaya Meningkatkan Pembelajaran Lempar Lembing Mealui Modifikasi Alat bola dan Lembing Berekor. (Skripsi). Fakultas Pendidikan Olahraga dan Kesehatan, Universitas Pendidikan Indonesia, Bandung. 
Syahfitri, A. (2016). Upaya Meningkatkan Hasil Belajar Lempar Lembing Dengan Memodifikasi Alat Bambu Pada Siswa VIII-A SMP Negri 3 Percut Sei. (Skripsi). Fakultas Ilmu Keolahragaan, UNIMED

Purnama. [online]. Teknik Dasar Lempar Lembing http://www.volimaniak.com/2014/10/teknik-dasar-lemparlembing.html. Diakses 9 Februari 2017 